\title{
The Rationality of Shifting Cultivation Systems: Labor Productivity Revisited
}

\author{
Uffe Nielsen, ${ }^{1}$ Ole Mertz, ${ }^{2}$ and Gabriel Tonga Noweg ${ }^{3}$
}

Published online: 23 May 2006

This paper reviews the theoretical and empirical literature on labor productivity in shifting cultivation systems, and relationships between labor productivity and production parameters are analyzed in two case studies of Iban communities in Sarawak, Malaysia, during two farming seasons. In addition, the labor productivity in shifting cultivation compared to off-farm wage labor opportunities is explored. Establishing firm relationships between labor productivity and production parameters, such as fallow length, fertilizer use, and herbicide use was not possible. We are thus unable to verify or reject the thesis that more labor is required for managing fields after short fallow compared to long fallow periods. We do demonstrate that shifting cultivation of hill rice can compete economically with common off-farm employment opportunities, and conclude that farmers' decisions to maintain their practices is based as much on economic rationales as on tradition.

KEY WORDS: fallow; Sarawak; swidden; slash and burn; labor productivity.

\section{INTRODUCTION}

Labor productivity in terms of crop output per labor input is a key element in understanding intensification processes in farming systems dominated by shifting cultivation practices. It is one of the core parameters in Ester Boserup's theory explaining why long fallow shifting cultivation was not intensified in areas with low population density-i.e., because the labor

${ }^{1}$ Department of Food Economics, Royal Veterinary and Agricultural University, Copenhagen, Denmark. Environmental Assessment Institute; e-mail: uni@imv.dk.

${ }^{2}$ Institute of Geography, University of Copenhagen, Denmark; e-mail: om@geogr.ku.dk.

${ }^{3}$ Faculty of Social Sciences, University Malaysia Sarawak, Malaysia; e-mail: gtnoweg@ calm.unimas.my. 